\title{
Comparison of safety and efficacy between laparoscopic myomectomy and traditional laparotomy for patients with uterine fibroids and their effect on pregnancy rate after surgery
}

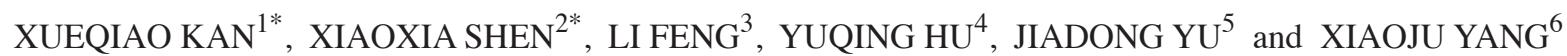 \\ ${ }^{1}$ Delivery Room, and ${ }^{2}$ Department of Nursing, Zhangqiu District Maternal and Child Health Care Hospital; \\ Departments of ${ }^{3}$ Obstetrics, ${ }^{4}$ Endocrinology and ${ }^{5}$ Personnel, The People's Hospital of Zhangqiu Area, Jinan, \\ Shandong 250200; ${ }^{6}$ Department of Obstetrics, East Hospital of Tongji University, Shanghai 200120, P.R. China
}

Received October 15, 2019; Accepted February 9, 2021

DOI: $10.3892 / \mathrm{etm} .2021 .10345$

\begin{abstract}
The aim of this retrospective study was to compare the safety and efficacy between laparoscopic myomectomy and traditional laparotomy for patients with uterine fibroids and determine their effect on the pregnancy rate after surgery. In total, 86 cases with uterine fibroids were selected among patients who were admitted in the Zhangqiu District Maternal and Child Health Care Hospital during the period of April, 2016 to April, 2017. Patients who underwent laparoscopic myomectomy were enrolled in group A $(n=42)$, and those who underwent traditional laparotomy were placed in group B $(\mathrm{n}=44)$. The general linear data and the operative indicators were compared. The VAS scores, serum IFN- $\gamma$, IL-6, VEGF levels and clinical efficacy of the two groups were also compared one week after surgery. Postoperative pregnancy rates and complications in both groups were also compared No significant differences were observed in general data between the two groups $(\mathrm{P}>0.05)$. The intra-operative blood loss in the group A was lower than that in group B $(\mathrm{P}<0.05)$, the average time of operation, hospital stays (days), and anal exhaust time in group A were shorter than those in group B $(\mathrm{P}<0.05)$. The pain degrees at 3, 6 and $18 \mathrm{~h}$ after surgery for patients in the group A were significantly lower than those of the group $\mathrm{B}(\mathrm{P}<0.05)$. There was no significant difference IL-6 and VEGF levels in the serum between groups $\mathrm{A}$ and $\mathrm{B}$ before and after surgery $(\mathrm{P}>0.05)$; however, the level of IFN- $\gamma$ expression, one week after surgery, in group B was significantly higher than that in group $\mathrm{A}(\mathrm{P}<0.05)$. The pregnancy rate in
\end{abstract}

Correspondence to: Dr Xiaoju Yang, Department of Obstetrics, East Hospital of Tongji University, 1800 Yuntai Road, Pudong, Shanghai 200120, P.R. China

E-mail: xkw2mm@163.com

*Contributed equally

Key words: laparoscopy, laparotomy, uterine fibroids, surgery, pregnancy rate the experimental group was higher than that in the control group $(\mathrm{P}<0.05)$, and the incidence rate of complications in group A was significantly lower than that in group $\mathrm{B}(\mathrm{P}<0.05)$. Results presented in the present study suggested that compared to traditional laparotomy, laparoscopic myomectomy is a more advantageous method in terms of safety, efficacy and pregnancy rate after surgery.

\section{Introduction}

Uterine fibroid is a common tumor in women with a relatively high prevalence rate in infertile patients (1). The tumor has smooth muscle and fibroblast components besides a large amount of extracellular matrix, which has an important influence on this disease. This is considered as a type of common clonal tumor and is also known as liomyoma or leiomyoma (2). Prior studies have shown that estrogen and progesterone can increase the growth rate of the tumor (3), while causing a series of grave and chronic symptoms. Excessive menstruation is the most common symptom, which can lead to anemia, fatigue and pain. In some cases, it may cause aperiodic pain, abdominal protrusion or pelvic pressure, which affects intestinal function and causes constipation (4). In addition, uterine fibroids have a great influence on the pregnancy rate of women $(5,6)$.

Traditionally, surgery for uterine fibroids, such as hysterectomy (7), requires open surgery. Although these treatments are of great benefit in the treatment of patients with uterine fibroids, these operations can easily lead to a series of complications such as urinary tract infection and pain (8). In recent years, more laparoscopic therapies, such as laparoscopic myomectomy, have been widely used for the treatment of these patients. Laparoscopic myomectomy technique has surpassed laparotomy and become the treatment option for many medical institutions worldwide. Compared with traditional laparotomy, laparoscopic myomectomy has several advantages. Some studies showed that laparoscopic myomectomy reduced morbidity and hospital stays compared with traditional surgical methods (9-12).

In this study, we compared the safety and efficacy of the two methods of surgeries and their influence on the pregnancy rate after surgery. 


\section{Materials and methods}

General information. This is a retrospective study. In total, 86 cases with uterine fibroids were selected among patients who were admitted in Zhangqiu District Maternal and Child Health Care Hospital during the period of April, 2016 to April, 2017. Patients who underwent laparoscopic myomectomy were enrolled in group A $(n=42)$, and those that underwent traditional laparotomy were included in group B $(n=44)$. Patients in group A were 26-46 years of age, with an average age of (35.59 \pm 4.02$)$ years, and patients in group B were 28-44 years, with an average age of $(36.01 \pm 3.97)$. Inclusion criteria were: i) Patients diagnosed with uterine fibroids after gynecological examination. ii) Family members were informed about this study. Exclusion criteria were: i) Age $(<25$ or $\geq 50)$; ii) primary ovarian insufficiency or tubal infertility; iii) a history of hemorrhagic diseases.

This study was approved by the ethics committee of the Zhangqiu District Maternal and Child Health Care Hospital. Patients signed the informed consent.

Methods. Patients in group A ( $\mathrm{n}=42)$ were treated with laparoscopic myomectomy. Abdominal endoscopy was performed using a $10-\mathrm{mm}$ endoscope equipped with a camera and a high-resolution monitor (Storz-France).

The following instruments were used: Atraumatic graspers, Semm fibroids for thermal coagulation, monopolar hooks, Semm needle holders and suture forceps, pelvicleaner (Storz-France). The instrument was introduced through three suprapubic puncture sites (diameter, $5 \mathrm{~mm}$ ). Laparoscopic myomectomy was performed in all cases according to the principle of non-invasive infertility surgery: Enlargement, careful hemostasis and irrigation with saline. Prior to surgery, the patient was required to first empty the bladder, then undergo general anesthesia, select the bladder lithotomy position and indwelling catheter. A $1-\mathrm{cm}$ incision was made in the skin of the umbilicus margin, and a pneumoperitoneum needle was inserted to construct a carbon dioxide pneumoperitoneum with a pressure of 12-14 mmHg. Subsequently, a laparoscopy device was inserted. Laparoscopy can prevent myometrial fragmentation after interstitial myomectomy or prevent the risk of large area $\left(>1 \mathrm{~cm}^{2}\right)$ adhesion after myomectomy by suturing a fine-closed uterine incision. The uterus was cut into one or two layers according to the depth of the incision, interrupting or running 3-0 Vicryl (Polyglactine 910, $20 \mathrm{~mm}$ needle; Ethicon) or 4-0 PDS (Polydioxanon, 20-mm needle; Ethicon) suture. After enlarging the incision $(20 \mathrm{~mm})$ with a single tooth retractor, myoma was removed through the suprapubic puncture site. The uterine incision was transparently closed using a classic needle hub placed via the suprapubic incision under laparoscopic control. In all cases, the peritoneal cavity was flushed with saline solution after the surgery was terminated.

Patients in group B $(n=44)$ were treated via traditional laparotomy. For laparoscopic myomectomy, the patient took the supine position after anesthesia, and a longitudinal incision was made in the middle of the lower abdomen. After slow injection of $20 \mathrm{ml}$ of normal saline $+6 \mathrm{U}$ of pituitrin into the myometrium, blunt separation was performed along the surface of the myoma capsule until reaching the area with more basal blood vessels. The myoma was then removed after clamping, and the myometrium and serosa were sutured.

Birth control lasted for 1 year for patients with large and frequent fibroids who underwent the intrauterine operation. This period was 6 months for those who did not undergo the intrauterine operation, and 3 months for patients without obvious uterine fibroids under the serosa.

Observation indicators. There were six observation indicators: i) The general linear data and operative indicators were compared. No significant differences were observed in the general data between the two groups $(\mathrm{P}>0.05)$. The operative indicators of patients in groups A and B, including average time of operation, intraoperative blood loss, hospital stays and anal exhaust time was also compared.

ii) The pain levels of patients in the two groups were compared at 3,6 and $18 \mathrm{~h}$ after surgery. The pain levels of the two groups were compared using the Visual Analogue Scale/Score (VAS) (13), with a score range of 0-10 points, and the score was proportional to the pain level.

iii) One week following surgery, the expression levels of IFN- $\gamma$, IL- 6 and VEGF in the serum were compared., between the two groups.

iv) The total effective rate was compared between the two groups. Evaluation criteria were: Markedly effective, uterine fibroids were completely excised without complications; effective, uterine fibroids were basically excised with no complications or complications could be recovered; ineffective, could not meet the effective standard. Total effective rate was calculated as marked efficiency + effective rate.

v) Comparison of the pregnancy rate after surgery between the two groups. Since the patients were childbearing age, the pregnancy rate after surgery between the two groups was compared. In order to investigate their pregnancy rate, follow-up visits were made after 6, 12, 18 and 24 months following the surgery.

vi) Complications observed in both groups were compared: There were three common postoperative complications after uterine fibroids and other laparoscopic surgery and laparotomy, i.e., urinary tract infection (14), incision pain (15), and pelvic adhesions (16). The complications were investigated and the incidence of complications was counted.

Statistical analysis. SPSS 19.0 (Asia Analytics Formerly SPSS) was used for statistical analysis of comprehensive data. The measurement data were expressed as mean \pm standard deviation. Independent samples t-tests was performed, and multiple group comparisons were performed using analysis of variance followed by LSD test. The count data were expressed by rate and composition ratio, and the Chi-square test was performed. $\mathrm{P}<0.05$ indicated a statistically significant difference.

\section{Results}

Comparison of the general clinical baseline data of the two groups. There was no statistically significant difference 
Table I. General clinical baseline data of groups A and B [n (\%)] (mean \pm SD).

\begin{tabular}{|c|c|c|c|c|}
\hline Variable & Group A $(n=42)$ & Group B $(n=44)$ & $\mathrm{t} / \chi^{2}$ & P-value \\
\hline Age (years) & $35.59 \pm 4.02$ & $36.01 \pm 3.97$ & 0.49 & 0.63 \\
\hline Unfertile phase (month) & $44.57 \pm 20.67$ & $41.99 \pm 20.17$ & 0.59 & 0.560 \\
\hline Body mass index $\left(\mathrm{kg} / \mathrm{m}^{2}\right)$ & $19.04 \pm 3.18$ & $19.15 \pm 2.64$ & 0.17 & 0.862 \\
\hline Total number of myomas & $2.75 \pm 1.98$ & $2.94 \pm 1.53$ & 0.50 & 0.619 \\
\hline Total number of large myomas & $1.12 \pm 0.33$ & $1.09 \pm 0.29$ & 0.45 & 0.655 \\
\hline Size of large large myomas $(\mathrm{cm})$ & $7.47 \pm 2.60$ & $7.07 \pm 2.54$ & 0.72 & 0.473 \\
\hline Smoking & & & 0.18 & 0.673 \\
\hline Yes & $23(54.76)$ & $24(54.55)$ & & \\
\hline No & $19(45.24)$ & $20(45.45)$ & & \\
\hline Drinking & & & 0.19 & 0.666 \\
\hline Yes & $22(52.38)$ & $21(47.73)$ & & \\
\hline No & $20(47.62)$ & $23(52.27)$ & & \\
\hline Obesity & & & 0.05 & 0.825 \\
\hline Yes & $20(47.62)$ & $22(50.00)$ & & \\
\hline No & $22(52.38)$ & $22(50.00)$ & & \\
\hline History of hypertension & & & 0.16 & 0.685 \\
\hline Yes & $23(54.76)$ & $26(61.90)$ & & \\
\hline No & $19(45.24)$ & $18(38.10)$ & & \\
\hline History of diabetes & & & 0.40 & 0.526 \\
\hline Yes & $21(50.00)$ & $25(56.82)$ & & \\
\hline No & $21(50.00)$ & $19(43.18)$ & & \\
\hline Location of myomas of patients & & & 0.68 & 0.711 \\
\hline Subserous myomas (\%) & $11(25.00)$ & $12(27.27)$ & & \\
\hline Intermural myomas (\%) & $29(69.05)$ & $28(63.64)$ & & \\
\hline Intra-uterine myomas $(\%)$ & $2(5.95)$ & $4 \quad(9.09)$ & & \\
\hline
\end{tabular}

Table II. Comparison of surgical indicators of patients between groups A and B.

\begin{tabular}{|c|c|c|c|c|}
\hline Variable & Group A $(n=42)$ & Group B $(n=44)$ & $\mathrm{t}$ & P-value \\
\hline Average time of operation (min) & $70.21 \pm 7.83$ & $100.23 \pm 38.34$ & 4.98 & $<0.001$ \\
\hline Average length of stay (days) & $8.12 \pm 2.01$ & $16.01 \pm 2.44$ & 16.32 & $<0.001$ \\
\hline Average intra-operative blood loss (ml) & $44.4 \pm 5.82$ & $79.22 \pm 7.53$ & 23.91 & $<0.001$ \\
\hline Average anal exhaust time (h) & $13.21 \pm 4.13$ & $29.25 \pm 5.37$ & 15.47 & $<0.001$ \\
\hline
\end{tabular}

in the general clinical baseline data including age, hypertension, hyperlipidemia, diabetes, personal hobbies such as smoking and drinking, between the groups $(\mathrm{P}>0.05)$ (Table I).

Comparison of the surgical indicators of patients between the two groups. The average time of operation, hospital stays, intra-operative blood loss, and anal exhaust time in the group A were $(70.21 \pm 7.83) \mathrm{min},(8.12 \pm 2.01)$ days, $(44.4 \pm 5.82) \mathrm{ml}$, and $(13.21 \pm 4.13) \mathrm{h}$, respectively. The average time of operation, intra-operative blood loss, hospital stays, and anal exhaust time in the group B were $(100.23 \pm 38.34) \mathrm{min},(16.01 \pm 2.44)$ days, $(79.22 \pm 7.53) \mathrm{ml}$, and $(29.25 \pm 5.37)$, respectively. By comparing the post-treatment surgical indicators in the two groups, it could be concluded that patients in group A were significantly better than those in group B and the results were statistically significant $(\mathrm{P}<0.001)$ (Table II).

VAS score after surgery. The pain scores of group A were $(4.21 \pm 0.83),(2.56 \pm 0.67),(1.63 \pm 0.55) 3,6$ and $18 \mathrm{~h}$ after surgery, respectively, while the pain scores of group B were $(8.23 \pm 0.94),(5.54 \pm 0.85)$ and $(3.70 \pm 0.61)$ at T0, T1 and T2 after surgery, respectively. As for intra-group comparison, the VAS score of the two groups decreased from T0 to T2, and the difference was statistically significant $(\mathrm{P}<0.05)$. As for comparison among groups, the VAS scores of group A at different time points were significantly lower than those of group $\mathrm{B}(\mathrm{P}<0.05)$. More details are presented in Table III. 
Table III. Average VAS score tables of patients in groups A and B at different time periods after surgery.

\begin{tabular}{|c|c|c|c|c|}
\hline Variable & Group A $(n=42)$ & Group B $(n=44)$ & $\mathrm{t}$ & P-value \\
\hline Three hours after surgery & $4.21 \pm 0.83$ & $8.23 \pm 0.94$ & 20.98 & $<0.001$ \\
\hline Six hours after surgery & $2.56 \pm 0.67$ & $5.54 \pm 0.85$ & 18.000 & $<0.001$ \\
\hline Eighteen hours after surgery & $1.63 \pm 0.55$ & $3.70 \pm 0.61$ & 16.500 & $<0.001$ \\
\hline $\mathrm{F}$ & 149.40 & 337.10 & & \\
\hline P-value & $<0.001$ & $<0.001$ & & \\
\hline
\end{tabular}

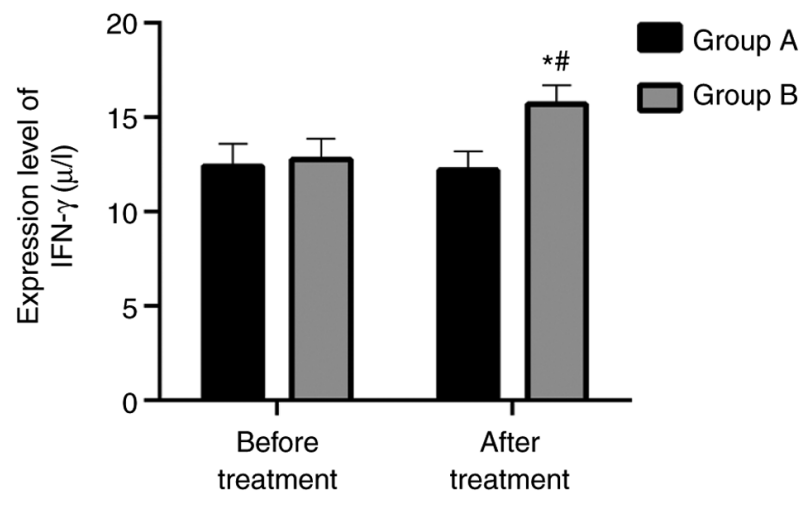

Figure 1. Comparison of the expression level of serum IFN- $\gamma$ of the two groups before and after treatment. There was no significant difference between the two groups before and after treatment in group $\mathrm{A}(\mathrm{P}>0.05)$, while the expression level of group B after treatment was higher than that before treatment, with statistically significant difference $(\mathrm{P}<0.05)$. The expression level of IFN- $\gamma$ in group B after treatment was significantly higher than that in group A, with statistically significant difference $(\mathrm{P}<0.05)$. "Comparison with group $\mathrm{A}(\mathrm{P}<0.05)$, and ${ }^{\#}$ comparison with after treatment $(\mathrm{P}<0.05)$.

Levels of serum related inflammatory factors in the two groups $I F N-\gamma$. Before and after treatment, the expression levels of IFN- $\gamma$ in group A were $(12.39 \pm 1.20) \mu \mathrm{g} / 1$ and $(12.18 \pm 1.01) \mu \mathrm{g} / 1$, respectively, while the expression levels of IFN- $\gamma$ in group B were $(12.76 \pm 1.09) \mu \mathrm{g} / 1$ and $(15.67 \pm 1.02) \mu \mathrm{g} / 1$, respectively. There was no significant difference between the two groups prior to treatment $(\mathrm{P}>0.05)$. There was no significant difference in group A before and after treatment $(\mathrm{P}>0.05)$. However, the expression level in group B after treatment was higher than that before treatment $(\mathrm{P}<0.05)$. After treatment, the expression level in group $\mathrm{B}$ was higher than that of group $\mathrm{A}(\mathrm{P}<0.05)$. More details are shown in Fig. 1.

IL6 $(\mathrm{pg} / \mathrm{ml})$. Before and after treatment, the expression levels of IL6 in group A were $(6.97 \pm 2.20) \mathrm{pg} / \mathrm{ml}$ and $(9.16 \pm 1.29) \mathrm{pg} / \mathrm{ml}$, respectively, and the expression levels of IL6 in group B were $(7.28 \pm 2.41) \mathrm{pg} / \mathrm{ml}$ and $(9.37 \pm 1.22) \mathrm{pg} / \mathrm{ml}$, respectively. There was no significant difference between the two groups before treatment $(\mathrm{P}>0.05)$. The expression levels in both groups after treatment were higher than those levels measured before treatment $(\mathrm{P}<0.05)$. Nevertheless there was no significant difference between the groups after treatment $(\mathrm{P}<0.05)$. More details are shown in Fig. 2.

VEGF $(\mathrm{pg} / \mathrm{ml})$. Before and after treatment, the expression levels of VEGF in group A were $(946.42 \pm 104.76) \mathrm{pg} / \mathrm{ml}$ and $(547.36 \pm 57.67) \mathrm{pg} / \mathrm{ml}$, respectively, and the expression

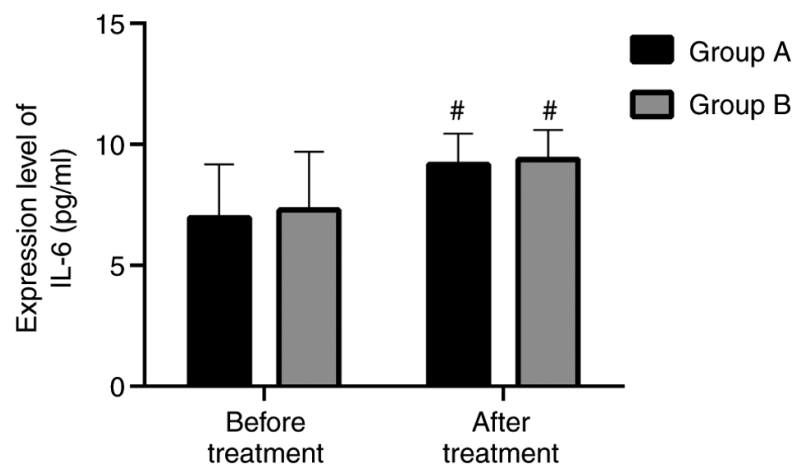

Figure 2. Comparison of the expression level of serum IL6 between the two groups before and after treatment. The expression level of IL- 6 after treatment was significantly higher than that before treatment, the difference was not statistically significant $(\mathrm{P}<0.05)$, and there was no difference between groups $\mathrm{A}$ and $\mathrm{B}$ before and after treatment $(\mathrm{P}>0.05)$. ${ }^{\#}$ Comparison with after treatment $(\mathrm{P}<0.05)$.

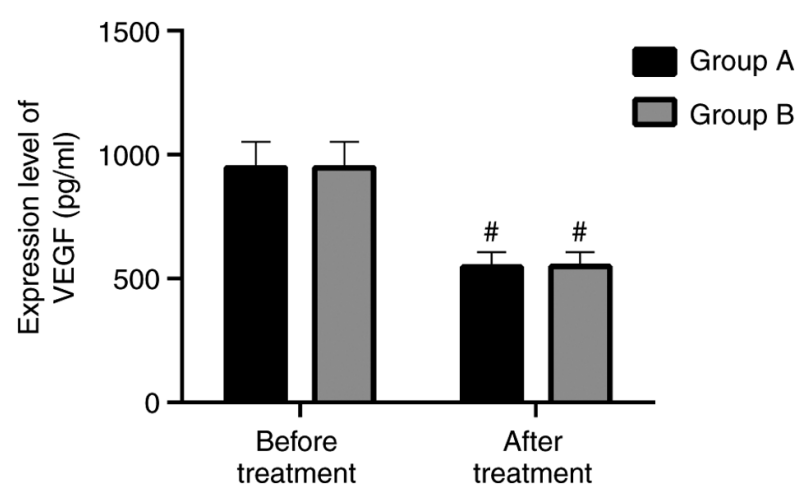

Figure 3. Comparison of the expression level of VEGF in serum-related cells of the two groups before and after treatment. The expression level of VEGF after treatment was significantly lower than that before treatment $(\mathrm{P}<0.05)$, and there was no difference in VEGF between groups $\mathrm{A}$ and $\mathrm{B}$ before and after treatment $(\mathrm{P}<0.0001)$. ${ }^{\#}$ Comparison after treatment $(\mathrm{P}<0.05)$.

levels of VEGF in group B were $(946.55 \pm 104.91) \mathrm{pg} / \mathrm{ml}$ and $(548.18 \pm 58.08) \mathrm{pg} / \mathrm{ml}$, respectively. There was no significant difference between the two groups prior to treatment $(\mathrm{P}>0.05)$. The expression levels in the two groups after treatment were higher than those levels registered before treatment $(\mathrm{P}<0.05)$. There was no significant difference between the groups after treatment $(\mathrm{P}<0.05)$. More details are presented in Fig. 3.

Total effective rate of patients in the two groups. Among the patients in group A, the total effective rate was: In 22 cases, 
Table IV. Total effective rate of patients in the two groups.

\begin{tabular}{lcccc}
\hline Efficacy & Group A $(\mathrm{n}=42)$ & Group B (n=44) & $\chi^{2}$ & P-value \\
\hline Markedly effective & $22(52.38)$ & $18(40.91)$ & - & - \\
Effective & $18(42.86)$ & $15(34.09)$ & - & - \\
Ineffective & $2(4.76)$ & $11(25.00)$ & - & - \\
Total effective rate (\%) & $40(95.24)$ & $33(75.00)$ & 6.86 & 0.009
\end{tabular}

Table V. Comparison of pregnancy rates between groups A and B.

\begin{tabular}{lccrr}
\hline Variable & Group A (n=42) & Group B (n=44) & $\chi^{2}$ & P-value \\
\hline Six months after surgery & $9(21.43)$ & $2(4.55)$ & 5.13 & 0.024 \\
Twelve months after surgery & $20(47.62)$ & $10(22.73)$ & 5.86 & 0.015 \\
Eighteen months after surgery & $29(69.05)$ & $19(43.18)$ & 5.83 & 0.016 \\
Twenty-four months after surgery & $38(90.48)$ & $26(59.09)$ & 11.12 & 0.001 \\
\hline
\end{tabular}

Table VI. Comparison of complications of patients between the two groups.

\begin{tabular}{lcccc}
\hline Variable & Group A (n=42) & Group B (n=44) & $\chi^{2}$ & P-value \\
\hline Urinary tract infection & $1(2.38)$ & $4(9.09)$ & - & - \\
Incision pain & $1(2.38)$ & $6(13.64)$ & - & - \\
Pelvic adhesion & $2(4.76)$ & $4(9.09)$ & - & - \\
Incidence rate of complications & $4(9.52)$ & $14(31.82)$ & 4.27 & 0.039 \\
\hline
\end{tabular}

markedly effective; in 18 cases, effective while 2 cases were ineffective. The overall total effective rate in group A were 95.24\%. In group B, 18 cases were markedly effective, 15 cases were effective while 11 cases were ineffective. The overall total effective rate in group B was $75.00 \%$. The total effective rate of group A was significantly higher than that of group B, and the difference was statistically significant $(\mathrm{P}<0.05)$. More details are shown in Table IV.

Comparison of the pregnancy rate after surgery between the two groups. In group A, 9 patients were pregnant at 6 months after surgery, with a pregnancy rate of $21.43 \%$; 20 at 12 months after surgery, with a pregnancy rate of $47.62 \%$; 29 at 18 months after surgery, with a pregnancy rate of $69.05 \%$ and 38 were pregnant at 24 months after surgery, with a pregnancy rate of $90.48 \%$. In group B, 2 patients were pregnant at 6 months after surgery, with a pregnancy rate of $4.55 \% ; 10$ at 12 months after surgery, with a pregnancy rate of $22.73 \%$; 19 were pregnant at 18 months after surgery, with a pregnancy rate of $43.18 \%$, and 26 at 24 months after surgery, with a pregnancy rate of $59.09 \%$. The pregnancy rate of group A was significantly higher than that of group B at these four time points. The difference was statistically significant $(\mathrm{P}<0.05)$. More details are shown in Table V.

Comparison of the complications of the two groups. The postoperative complications including infection, incision pain and pelvic adhesion were studied in both groups. In group A, there was 1 case of infection, 1 case of incision pain and 2 cases of pelvic adhesion, with a total incidence rate of complications of $9.52 \%$. In group B, there were 4 cases of infection, 6 cases of incision pain and 4 cases of pelvic adhesion, with a total incidence rate of complications of $31.82 \%$. The incidence rate of complications after surgery in group A was significantly lower than that of group $B$, with significant difference $(\mathrm{P}<0.05)$. More details are presented in Table VI.

\section{Discussion}

Uterine fibroids are very common in gynecology, and they have adverse effects on women and pregnancy $(17,18)$. However, it is very important to choose an effective therapy that can effectively and safely treat uterine fibroids. The focus of the present study was to compare laparoscopic myomectomy with traditional laparotomy methods for treating uterine fibroids.

In this study, the average time of operation, blood loss, hospital stays and exhaust time of groups A and B were compared, and results showed that laparoscopic therapy had significantly shorter time of operation, less blood loss and significantly less hospital stays and average exhaust time. Results obtained from prior studies revealed that laparoscopic myomectomy could simply lead to serious blood loss, resulting in severe problems such as increased incidence rate of postoperative illnesses $(19,20)$. However, the blood loss 
in the laparoscopic myomectomy method is less than that of laparotomy. Previous findings showed that compared with laparotomy, laparoscopic myomectomy method significantly reduced blood loss $(21,22)$. In addition, compares to laparoscopy, patients treated with laparoscopic myomectomy recover faster and better from laparoscopy. Patients treated with laparoscopic myomectomy also had a shorter hospital stay $(23,24)$. All these observations could explain the reason for the average time of operation, blood loss and hospital stays of laparoscopic myomectomy surgery being better than those of laparotomy.

Compared with laparotomy, laparoscopic myomectomy could reduce postoperative pain by effectively reducing the oxidative stress reaction of postoperative uterine fibroids (25). Results obtained from comparing the VAS scores between the two groups after 3, 6 and $12 \mathrm{~h}$, demonstrated that patients in group B had a higher pain VAS score. Bhave Chittawar et al reported that laparoscopic myomectomy was a less painful surgery compared with traditional laparotomy (26). Results showed that laparoscopic surgery caused less postoperative pain compared to traditional transabdominal surgery.

In the present study, we compared the levels of serum IFN- $\gamma$, IL- 6 and VEGF in both groups one week after surgery, and found that the expression level of IFN- $\gamma$ in group B after treatment was significantly higher, while the levels of IL- 6 and VEGF between the two groups were not significantly different after treatment. Prior findings showed that IFN- $\gamma$ could inhibit tumor level in uterine fibroids. High expression level of IFN- $\gamma$ can inhibit gonadotropin synthesis and affect the normal body function. However, the expression level of IFN- $\gamma$ after surgery in laparoscopic myomectomy was lower than that in traditional laparotomy, indicating that laparoscopic myomectomy could improve IFN- $\gamma$ and the efficacy was more significant than that of traditional methods (27). By comparing the postoperative serum factors such as IFN- $\gamma$ and the total effective rate of the disease in the two groups, it was shown that laparoscopic hysteromyoma surgery has better efficacy than traditional laparotomy.

The pregnancy rate for patients with uterine fibroids is usually very low (28), and this problem can be alleviated only through surgery. After comparing the pregnancy rates of the two groups at different time points $(6,12,18$ and 24 months) after surgery, we found that the pregnancy rate after laparoscopic myomectomy was higher than that of the alternative method. Results obtained from prior studies indicated that uterine rupture caused by myomectomy was particularly risky to pregnancy (29). Koo et al reported that the uterine rupture caused by laparoscopy was a rare event (30) with minimal effects on pregnancy rate. Shen et al also showed (31) that the pregnancy rate was higher after laparoscopic myomectomy.

Sheyn et al reported that, compared with traditional abdominal myomectomy, laparoscopic myomectomy had a lower incidence rate of complications (32). The results of the present study showed that the incidence rate of complications in patients treated with laparoscopic myomectomy were significantly lower than that of traditional laparotomy. Our findings are in accordance with previous reports.

Other studies have reported a close association among the size of fibroids, number of fibroids and the risk of complications (33). We also should not underestimate the importance of traditional laparotomy for patients with numerous large fibroids $(34,35)$.

From the incidence of these complications, combined with the previous inflammatory factors, surgical indicators, VAS scores, and pregnancy rate, patients who underwent laparoscopy have smaller wounds, less bleeding volume, less inflammation, and less pain than traditional open surgery. In this way, patients have fewer postoperative complications and can recover faster. Owing to its less pain and faster recovery, patients' quality of life is less affected, which can be very beneficial to their chance for future pregnancies. In the clinical study of Gueli Alletti et al (36) on ovarian cancer, it was found that if a patient needs to get a good recovery, he has to stay positive, and negative emotions are likely to aggravate the patient's condition. Therefore, it is necessary to avoid such negative emotions in the clinical practice. The same is true for the treatment of uterine fibroids. The use of laparoscopy is currently a trend. If surgical methods are modified to reduce their risks, the use of laparoscopy will be more widespread in the future. In this case, the effect becomes higher, and it is more beneficial for women's pregnancy rate.

There were some shortcomings associated with this study, for example the variety of uterine fibroids was limited, there were no patients with large myoma, and finally our sample size was small. In summary, laparoscopic myomectomy on uterine fibroids has advantages over traditional laparotomy. At the same time, in the future research and treatment, the existing laparoscopic therapy remains to be ameliorated, the risk of surgery reduced and the efficacy of surgery should be improved.

\section{Acknowledgements}

Not applicable.

\section{Funding}

No funding was received.

\section{Availability of data and materials}

The datasets used and/or analyzed during the present study are available from the corresponding author on reasonable request.

\section{Authors' contributions}

$\mathrm{XK}$ and XS conceived and designed the study and drafted the manuscript. LF and YH collected, analyzed and interpreted the experimental data. JY and XY analyzed data and revised the manuscript for important intellectual content. XK wrote the manuscript. XK and LF are responsible for confirming authenticity of the data. All authors read and approved the final manuscript.

\section{Ethics approval and consent to participate}

The study was approved by the Ethics Committee of Zhangqiu District Maternal and Child Health Care Hospital. Patients signed the informed consent. 


\section{Patient consent for publication}

Not applicable.

\section{Competing interests}

The authors declare that they have no competing interests.

\section{References}

1. Zepiridis LI, Grimbizis GF and Tarlatzis BC: Infertility and uterine fibroids. Best Pract Res Clin Obstet Gynaecol 34: 66-73, 2016.

2. Grube M, Neis F, Brucker SY, Kommoss S, Andress J, Weiss M, Hoffmann S, Taran FA and Krämer B: Uterine fibroids-current trends and strategies. Surg Technol Int 34: 257-263, 2019.

3. Sparić R: Uterine myomas in pregnancy, childbirth and puerperium. Srp Arh Celok Lek 142: 118-124, 2014 (In Serbian).

4. Stewart EA, Cookson CL, Gandolfo RA and Schulze-Rath R: Epidemiology of uterine fibroids: A systematic review. BJOG 124: 1501-1512, 2017.

5. Levast F, Legendre G, Bouet PE and Sentilhes L: Management of uterine myomas during pregnancy. Gynecol Obstet Fertil 44: 350-354, 2016 (In French).

6. De Vivo A, Mancuso A, Giacobbe A, Savasta LM, De Dominici R, Dugo N, Dugo C and Vaiarelli A: Uterine myomas during pregnancy: A longitudinal sonographic study. Ultrasound Obstet Gynecol 37: 361-365, 2011.

7. Gil-Moreno A, Carbonell-Socias M, Salicrú S, Bradbury M, García Á, Vergés R, Puig OP, Sánchez-Iglesias JL, Cabrera-Díaz S, de la Torre J, et al: Nerve-sparing versus non-nerve-sparing radical hysterectomy: Surgical and long-term oncological outcomes. Oncotarget 10: 4598-4608, 2019.

8. Mettler L, Schollmeyer T, Tinelli A, Malvasi A and Alkatout I: Complications of uterine fibroids and their management, surgical management of fibroids, laparoscopy and hysteroscopy versus hysterectomy, haemorrhage, adhesions, and complications. Obstet Gynecol Int 2012: 791248, 2012.

9. Venturella R, Rocca ML, Lico D, La Ferrera N, Cirillo R, Gizzo S, Morelli M, Zupi E and Zullo F: In-bag manual versus uncontained power morcellation for laparoscopic myomectomy: Randomized controlled trial. Fertil Steril 105: 1369-1376, 2016.

10. Rossetti A, Sizzi O, Soranna L, Cucinelli F, Mancuso S and Lanzone A: Long-term results of laparoscopic myomectomy: Recurrence rate in comparison with abdominal myomectomy. Hum Reprod 16: 770-774, 2001.

11. Fujimoto A, Morimoto C, Hosokawa $\mathrm{Y}$ and Hasegawa A: Suturing method as a factor for uterine vascularity after laparoscopic myomectomy. Eur J Obstet Gynecol Reprod Biol 211: 146-149, 2017.

12. Solnik MJ and Munro MG: Indications and alternatives to hysterectomy. Clin Obstet Gynecol 57: 14-42, 2014.

13. Pointer JS: A novel visual analogue scale (VAS) device: An instrument based on the VAS designed to quantify the subjective visual experience. Ophthalmic Physiol Opt 24: 181-185, 2004.

14. Chigbu B, Onwere S, Kamanu C, Aluka C, Okoro O, Feyi-Waboso $\mathrm{P}$ and Onichakwe C: Lessons learned from the outcome of bloodless emergency laparotomies on Jehovah's Witness women presenting in the extremis with ruptured uterus. Arch Gynecol Obstet 279: 469-472, 2009.

15. Wu JL, Wang F, Liang X, Liang X, Xu CF and Xin G: Effect of thoracoscopic esophagus cancer surgery on postoperative incision pain as well as non-specific and specific immune response. J Hainan Med University 23: 153-156, 2017.

16. Indar AA, Efron JE and Young-Fadok TM: Laparoscopic ileal pouch-anal anastomosis reduces abdominal and pelvic adhesions. Surg Endosc 23: 174-177, 2009.

17. Ikhena DE and Bulun SE: Literature review on the role of uterine fibroids in endometrial function. Reprod Sci 25: 635-643, 2018.

18. Sabry M and Al-Hendy A: Medical treatment of uterine leiomyoma. Reprod Sci 19: 339-353, 2012.
19. Conforti A, Mollo A, Alviggi C, Tsimpanakos I, Strina I, Magos A and De Placido G: Techniques to reduce blood loss during open myomectomy: A qualitative review of literature. Eur J Obstet Gynecol Reprod Biol 192: 90-95, 2015.

20. Clark NV, Wang KC, Opoku-Anane J, Hill-Lydecker CI, Vitonis AF, Einarsson JI and Cohen SL: The menstrual cycle and blood loss during laparoscopic myomectomy. Acta Obstet Gynecol Scand 96: 1446-1452, 2017.

21. Ji L, Jin L and Hu M: Laparoscopic myomectomy with temporary bilateral uterine artery occlusion compared with traditional surgery for uterine myomas: Blood loss and recurrence. J Minim Invasive Gynecol 25: 434-439, 2018.

22. Choi SH, Hong S, Kim M, Bae HS, Kim MK, Kim ML, Jung YW, Yun BS and Seong SJ: Robotic-assisted laparoscopic myomectomy: The feasibility in single-site system. Obstet Gynecol Sci 62: 56-64, 2019.

23. Chen I, Lisonkova S, Joseph KS, Williams C, Yong P and Allaire C: Laparoscopic versus abdominal myomectomy: Practice patterns and health care use in British Columbia. J Obstet Gynaecol Can 36: 817-821, 2014.

24. D'Silva EC, Muda AM, Safiee AI and Ghazali WAHW: Five-Year lapsed: Review of laparoscopic myomectomy versus open myomectomy in putrajaya hospital. Gynecol Minim Invasive Ther 7: 161-166, 2018.

25. Tomasik P, Bomba-Opon D, Krupniewski L, Palczewski P and Wielgos M: Evaluation of uterine myomas during pregnancy using magnetic resonance imaging. Neuro Endocrinol Lett 35: 262-264, 2014.

26. Bhave Chittawar P, Franik S, Pouwer AW and Farquhar C: Minimally invasive surgical techniques versus open myomectomy for uterine fibroids. Cochrane Database Syst Rev 21: CD004638, 2014.

27. Ong SJ, Tang YZ and Shaida N: The role of clinical radiology in the management of uterine fibroids. Br J Hosp Med (Lond) 80: C66-C69, 2019.

28. Sunkara SK, Khairy M, El-Toukhy T, Khalaf Y and Coomarasamy A: The effect of intramural fibroids without uterine cavity involvement on the outcome of IVF treatment: A systematic review and meta-analysis. Hum Reprod 25: 418-429, 2010.

29. Pakniat H, Soofizadeh N and Khezri MB: Spontaneous uterine rupture after abdominal myomectomy at the gestational age of 20 weeks in pregnancy: A case report. Int J Reprod Biomed 14: 483-486, 2016

30. Koo YJ, Lee JK, Lee YK, Kwak DW, Lee IH, Lim KT, Lee KH and Kim TJ: Pregnancy outcomes and risk factors for uterine rupture after laparoscopic myomectomy: A single-center experience and literature review. J Minim Invasive Gynecol 22: 1022-1028, 2015.

31. Shen Q, Chen M, Wang Y, Zhou Q, Tao X, Zhang W and Zhu X: Effects of laparoscopic versus minilaparotomic myomectomy on uterine leiomyoma: A meta-analysis. J Minim Invasive Gynecol 22: 177-184, 2015.

32. Sheyn D, Bretschnieder CE, Mahajan ST, El-Nashar S, Billow M and Ninivaggio CS: Comparison of 30-day complication between myomectomy and total hysterectomy for the treatment of uterine fibroids in women older than age 40. J Minim Invasive Gynecol 26: 1076-1082, 2019.

33. Lohle PNM, Higué D and Herbreteau D: Uterine artery embolisation in women with symptomatic uterine fibroids. Presse Med 48: 440-446, 2019.

34. Kotani Y, Tobiume T, Fujishima R, Shigeta M, Takaya H, Nakai H, Suzuki A, Tsuji I, Mandai M and Matsumura N: Recurrence of uterine myoma after myomectomy: Open myomectomy versus laparoscopic myomectomy. J Obstet Gynaecol Res 44: 298-302, 2018.

35. Rogers TS and Bieck AM: Management of uterine fibroids. Am Fam Physician 99: 330-333, 2019.

36. Gueli Alletti S, Vizzielli G, Lafuenti L, Costantini B, Fagotti A, Fedele C, Cianci S, Perrone E, Gallotta V, Rossitto C and Scambia G: Single-institution propensity-matched study to evaluate the psychological effect of minimally invasive interval debulking surgery versus standard laparotomic treatment: From body to mind and back. J Minim Invasive Gynecol 25: 816-822, 2018. 